\title{
Evaluation of denitration of nitrocellulose by microbiological treatment for industrial waste effluents using calorimetry analysis
}

\author{
Elena A. Saratovskikh ${ }^{1} \cdot$ Lidia V. Avdeeva ${ }^{1} \cdot$ Rashit N. Yarullin² $^{2}$ Anatoly I. Kazakov ${ }^{1}$
}

Received: 17 May 2018/Accepted: 12 August 2018/Published online: 24 August 2018

(c) Akadémiai Kiadó, Budapest, Hungary 2018

\begin{abstract}
The problem of utilization of the compounds present in the effluents of the production of cellulose nitrates (NC) is very important and complicated, and its decision is inextricably related to the environment. The process of heat release in the samples of nitrocellulose subjected to biological processing of different types was studied. Biological processing was conducted by incubation with sulfate-reducing bacteria Desulfovibrio desulfuricans BKMB-1388, microscopic fungi Fusarium solani BKM F-819, and their mixed culture. The studies were carried out on the native NC (13.38\% nitrogen) and the $\mathrm{NC}$ processed $\left(\mathrm{NC}_{\text {proc }}\right)$ using ultraviolet radiation and ozone (UV + ozone). It has been shown that the pretreatment of the NC by UV + ozone significantly increases the degree of decomposition of the NC during its subsequent biodegradation assisted by symbiotic microorganisms of $D$. desulfuricans and $F$. solani. A substantial result was achieved on the fifth day of $\mathrm{NC}_{\text {proc }}$ incubation, which is promising from the viewpoint of practical applications.
\end{abstract}

Keywords Nitrocellulose $\cdot$ Biological degradation $\cdot$ Fusarium solani $\cdot$ Desulfovibrio desulfuricans $\cdot$ Calorimetry

\section{Introduction}

High-energy capacity materials such as aromatic compounds, nitroesters, and nitroamines are components of polymeric composite materials. Large amounts of effluents with wastes containing environmentally hazardous substances are formed in the process of industrial production of such polymers. The problem of their utilization is important and complicated, and its decision is inextricably related to health of the present and future generations of people. The development of methods and techniques aimed at accelerating the decomposition of the compounds present in the effluents of the production of cellulose nitrates (NC) will allow one to solve environmental problems associated with the accumulation of large quantities of flammable, explosive, and poorly degradable materials in

Elena A. Saratovskikh

easar@icp.ac.ru

1 Institute of Problems of Chemical Physics, RAS, Chernogolovka, Russian Federation 142432

2 Kazan (Volga region), Federal University, Kazan, Russian Federation 420008 the sediment ponds and to reduce the negative impact on the environment.

The volumes of NC production in the world are very considerable. It is known [1] that Germany produced 26,050 tons of gunpowder within the period from January to March 1945. The scientific base of special chemistry in the USA is concentrated in the state enterprises, such as Livermore, Argonne, and Los Alamos National laboratories and the research center at the China Lake. Twenty-six plants producing gun powders, solid propellants, and explosives were placed in the 1980s in these cities [2].

Investigations in this area are aimed at searching for the possibility of prolonged and safe storage of $\mathrm{NC}$ [3] and eliminating the main drawbacks of NC. These are low density, high fragility, and low combustion temperature. The modification of the NC precursor was used in [4]. Microcrystalline cellulose nitrate was successfully prepared from Alfa grass (a cheap and easily renewable source) and showed a high potential for the use as a component of propellants. It is also proposed [5] to prepare a nanometallic fuel based on NC modified by nanoborane. The introduction of nanoborane by electrospinning into nitrocellulose fibers induces a faster and intensive combustion. 
However, NC also finds other spheres of application. Nitrated cellulose with a low nitrogen content (lower than $12.5 \%$ ) is used as coatings, varnishes, and paintings and in microelectronics. Nitrated cellulose with a high nitrogen content (higher than 12.5\%) is used as the major component of many propellants, fireworks, explosives, and gas generators.

Nitrated cellulose was used $[6,7]$ as an additive to improve thermal characteristics and mechanical properties of propellants. The use of the polymer based on glycidyl azide with the same purpose showed [8] that the initial decomposition temperature was $5.67^{\circ} \mathrm{C}$ higher than that of purely spherical NC powders, which is very important for safety characteristics.

The most promising and environmentally friendly are biological methods for the disposal of industrial effluents as well as the wastes accumulated in the sediment ponds $[9,10]$. However, it is known that the cellulose and its nitrated derivatives are characterized by high resistance to biological degradation [11]. Nevertheless, works in this direction are persistently continued. There is an evidence for the partial destruction of the NC with the use of fungi [12-14] and bacteria [15-17] or when processes are conducted in anaerobic bioreactors [18]. The preliminary chemical or physicochemical treatment is used to obtain substances that are easily assimilated by microorganisms [19].

Cellulose nitrate is a basis for the production of gun powders, which are explosives that decompose to release a significant quantity of energy within a short time period. Therefore, the characteristics of the thermal decomposition of $\mathrm{NC}$ are among the most important parameters for the establishment of the mechanism and rate of decomposition. Thus, they provide a clear representation about the maximum possible comparative stability of this highly explosive substance.

Multiple methods, primarily, the determination of nitrogen, nitrates, and nitrites, are used in laboratory research as well as in monitoring the technological process of NC degradation. One of the most important and highly informative indicators is the heat release rate and the total heat of decomposition of the $\mathrm{NC}$ isolated from the solution after microbial degradation. The results of calorimetric studies allow one to examine the full thermodynamic characteristic of the phenomenon under study and to draw exacter conclusions and predictions. It is typical that the thermodynamic approach is being more widely used in biology as a precise method for the investigation of processes in living organisms. The parameters of heat release characterize the degree of denitration of NC.

Thermogravimetric analysis is efficiently used in all numerous studies [1-8]. Thermogravimetric analysis (TG) and differential scanning calorimetry (DSC) of NC raw materials and mixtures used in the production of pyrotechnical firecrackers, guns, and other units were monitored under different conditions and in various processes of mixing in air [20]. It was found by TG and DSC that the temperature of the environment used for drying the initial mixture, the high relative moisture content, and granulation did not induce self-ignition.

Microencapsulation of ammonium azide particles with fibrous NC was carried out both in solvent and without solvent [21]. X-ray diffractometry, scanning electron microscopy, infrared spectroscopy, TG, and DSC were used to characterize the structure, morphology, and thermal stability of these particles. The results of the study [21] showed that the efficiency of the proposed thermogravimetric method is more informative than that of a sequence of other complicated methods.

The thermal characteristics of the propellant before designing the industrial setup for the combustion of propellants with expired storage term were also determined by TG in argon [22].

The listed above and other industrial productions for the synthesis and use of $\mathrm{NC}$ give large volumes of wastewater. Therefore, wastewater decontamination and the possibility of repeated use in the technological cycle are important tasks of the modern ecological chemistry. Various microorganisms or active silt from purification plants (being a secondary power source) is used for the solution of this complicated problem [23].

The microbiological NC degradation with the sulfatereducing bacteria Desulfovibrio desulfuricans [19] and filamentous fungus Fusarium solani [24, 25] has been studied, and the influence of the preliminary $\mathrm{NC}$ treatment on the process when UV-irradiation and ozone are used has been considered.

In this work, the possibility of using UV radiation combined with ozone and the mixed culture of the fungus Fusarium solani BKMF-819 and sulfate-reducing bacteria Desulfovibrio desulfuricans BKMB-1388 on the NC in the wastewater treatment in the industrial production and detoxification in the sediment ponds was evaluated. For comparison of the whole body of such a vast amount of data and for choosing the most efficient microbiological treatment conditions, the evaluation method was applied to one of the characteristic parameters, namely the heat of thermal decomposition of $\mathrm{NC}$ samples isolated from the solution after the microbiological treatment, since it is known that the heat of NC thermal decomposition increases with an increase in the nitrogen content in the sample.

The aim of this work is to evaluate the degree of microbiological degradation of $\mathrm{NC}$ under the influence of different types of microorganisms. The heat of thermal decomposition of selected NC samples is used as a parameter of the degradation process. We also intended to 
choose which of the variants of microbial degradation of $\mathrm{NC}$ would be most suitable for the industrial use.

\section{Experimental}

\section{Materials and methods}

The following reagents and solvents manufactured by Sigma (USA), BioRad (USA), and Reakhim (Russia) were used: $\mathrm{KCl}, \mathrm{NH}_{4} \mathrm{Cl}, \mathrm{CaCl}_{2} \times 2 \mathrm{H}_{2} \mathrm{O}, \mathrm{K}_{2} \mathrm{HPO}_{4}, \mathrm{MgCl}_{2} \times 6 \mathrm{H}_{2} \mathrm{O}$, $\mathrm{NaNO}_{3}, \mathrm{Na}$ lactate, $\mathrm{Na}$ salicylate, $\mathrm{NaOH}$, glucose, tetrahydrofuran (THF), and acetone. They were used for the preparation of nutrient culture media and buffer systems and in the physicochemical studies. The NC samples (trade mark M/l 26 432-01) with a nitrogen content of $13.38 \%$ (mass of an elementary unit of a macromolecule is 284.4 , degree of polymerization is 1140 , molecular weight is 324,216 ) according to GOST R 50461-92 provided by the Kazan Gunpowder Plant were used.

\section{Treatment of NC by ultraviolet light and ozone}

Ultraviolet irradiation and ozonation (UV + ozone) were used for the pretreatment of $\mathrm{NC}$ taken in an initial concentration of $10 \mathrm{~g} \mathrm{~L}^{-1}$. The photochemical reaction was carried out in a round-bottom quartz reactor with an inner diameter of $10.0 \mathrm{~cm}$ and a volume of $500 \mathrm{~mL}$. The reactor was installed at a distance of $4 \mathrm{~cm}$ from the radiation source. The arc mercury discharge lamp with the luminophore of the high-pressure $400 \mathrm{~W}$ DRL-400 lamp (trademark E 40) manufactured at the OAO Lisma (Russia) was used for irradiation. The wavelength range was $250-600 \mathrm{~nm}$, and the luminous flux in the UV range was 24,000 $\mathrm{lm}$.

The ozonator manufactured at the IPCP RAS with the volume rate of the oxygen purge $Q_{\mathrm{O} 2} \approx 350 \mathrm{~cm}^{3} \mathrm{~min}^{-1}$ $=21 \mathrm{~L} \mathrm{~h}^{-1}$ was used as a source of ozone. At the $2.5 \%$ content of ozone in oxygen, the ozonator capacity was about $0.5 \mathrm{~L} \mathrm{O}_{3} / \mathrm{h}=1.125 \mathrm{~g} \mathrm{O}_{3} / \mathrm{h}$. The native $\mathrm{NC}$ solution was purged with ozone through a capillary.

The samples of $10 \mathrm{~mL}$ of the mixture were taken at an interval of $1,3,7,12$, and $27 \mathrm{~h}$ from the onset of experiment to determine the $\mathrm{pH}$ of the reaction solution and the nitrogen content in the NC.

\section{Microorganisms}

The mycelial fungus Fusarium solani BKMF-819 and sulfate-reducing bacteria Desulfovibrio desulfuricans (strain BKM B-1388) obtained from the All-Russia Collection of Microorganisms (G.K. Skryabin Institute of
Biochemistry and Physiology of Microorganisms, Russian Academy of Sciences) were used.

\section{Bacteria biomass increasing}

For increasing the biomass, the strain of $D$. desulfuricans BKMB-1388 was cultivated on the medium enriched with $\mathrm{Na}$ lactate $(50 \mathrm{mM})$ and $\mathrm{Na}$ sulfate $(10 \mathrm{mM})$ with the formation of sulfide $(9.8 \mathrm{mM})$ on the fifth day of cultivation. The sowing was performed in the Hungate vials and incubated at $30^{\circ} \mathrm{C}$. The biomass of the bacteria was cultured anaerobically in medical bottles $250 \mathrm{~mL}$ in volume with the working volume of the medium of the sulfate reducer (DSV) equal to $100 \mathrm{~mL}$. The absorbance of the culture fluid (at the wavelength $\lambda=600 \mathrm{~nm}$ ) in 7 days of the incubation was $0.34-0.35$, which corresponded to $(6.5-8.5) \times 10^{8}$ cells in $1 \mathrm{~mL}$ of the cultivation medium.

\section{Medium for sulfate reducer growth}

The medium for sulfate reducer growth was prepared from solutions 1, 2, and 3. Solution 1: $\mathrm{KH}_{2} \mathrm{PO}_{4} 0.5 \mathrm{~g}, \mathrm{NH}_{4} \mathrm{Cl}$ $1.0 \mathrm{~g}, \quad \mathrm{Na}_{2} \mathrm{SO}_{4} 1.0 \mathrm{~g}, \quad \mathrm{CaCl}_{2} \times 2 \mathrm{H}_{2} \mathrm{O} \quad 0.1 \mathrm{~g}, \quad \mathrm{MgSO}_{4-}$ $\times 7 \mathrm{H}_{2} \mathrm{O} 2.0 \mathrm{~g}$, Na DL-lactate $2.0 \mathrm{~g}$, yeast extract $1.0 \mathrm{~g}$, resazurin $1.0 \mathrm{mg}$, Wolin vitamin $10 \mathrm{~mL}$, trace (micro) elements SL-10 $1 \mathrm{~mL}$, and distilled water $980.0 \mathrm{ml}$. Solution 2: $\mathrm{FeSO}_{4} \times 7 \mathrm{H}_{2} \mathrm{O} 0.5 \mathrm{~g}$ and distilled water $10 \mathrm{~mL}$. Solution 3: Na thioglycolate $0.1 \mathrm{~g}$, ascorbic acid $0.1 \mathrm{~g}$, and distilled water $10 \mathrm{~mL}$. The solution of microelements contained $\left(\mathrm{mg} \mathrm{L}^{-1}\right): \mathrm{FeCl}_{3} \times 4 \mathrm{H}_{2} \mathrm{O} 1500, \mathrm{ZnCl}_{2}$ 70.0, $\mathrm{MnCl}_{2} \times 4 \mathrm{H}_{2} \mathrm{O} 100.0, \mathrm{H}_{3} \mathrm{BO}_{3} 6.0, \mathrm{CoCl}_{2} \times 6 \mathrm{H}_{2} \mathrm{O} 190.0$, $\mathrm{CuCl}_{2} \times 2 \mathrm{H}_{2} \mathrm{O} \quad 2.0, \quad \mathrm{NiCl}_{2} \times 6 \mathrm{H}_{2} \mathrm{O} \quad 24.0, \quad \mathrm{Na}_{2} \mathrm{MoO}_{4-}$ $\times 2 \mathrm{H}_{2} \mathrm{O} 36.0$, and $10.0 \mathrm{~mL} \mathrm{HCl}(25 \%, 7.7 \mathrm{M})$. The solution of Wolin vitamins contained $\left(\mathrm{mg} \mathrm{L}^{-1}\right)$ : biotin 2.0 , folic acid 2.0, pyridoxine- $\mathrm{HCl} 10.0$, thiamine- $\mathrm{HCl} 5.0$, riboflavin 5.0, nicotinic acid 5.0, DL-calcium pantothenate 5.0, vitamin B12 0.1, p-aminobenzoic acid 5.0, and lipoic acid 5.0.

To prepare the medium, the ingredients of each solution were dissolved in an appropriate amount of water. Solution 1 was boiled for about $1 \mathrm{~min}$ and then cooled to room temperature purging $100 \% \mathrm{~N}_{2}$. Then, solutions 2 and 3 were added to bring the $\mathrm{pH}$ to 7.8 with $\mathrm{NaOH}$, and the mixture was dispensed aerobically under $100 \% \mathrm{~N}_{2}$ in tubes or vials. During the preparation, the medium was continuously stirred, keeping the gray precipitate suspended. Sterilization was conducted in the autoclave for $15 \mathrm{~min}$ at $121^{\circ} \mathrm{C}$. 


\section{Medium for experiments on NC microbiological degradation}

For the preparation of the culture nutrient medium to study the $\mathrm{NC}$ biodegradation, the following reagents were used: $\mathrm{KCl} 5.0 \mathrm{~g}, \mathrm{NH}_{4} \mathrm{Cl} 10 \mathrm{~g}, \mathrm{CaCl}_{2} \times 2 \mathrm{H}_{2} \mathrm{O} 1 \mathrm{~g}, \mathrm{~K}_{2} \mathrm{HPO}_{4} 10 \mathrm{~g}$, $\mathrm{MgCl}_{2} \times 6 \mathrm{H}_{2} \mathrm{O} 20 \mathrm{~g}$, yeast extract $10 \mathrm{~g}$, Na lactate $60 \mathrm{~mL}$, and glucose $20 \mathrm{~g}$. The components were dissolved in distilled water $(21)$. The resulting concentrate of the culture nutrient medium before the experiment was diluted in a ratio of $1: 4$ with distilled water.

The necessary quantity of bacteria for the cultivation was quickly injected with a syringe into a laboratory reactor and stirred. Before sowing, the $\mathrm{pH}$ was $6.5-7.0$. The incubation temperature of the bacteria was maintained throughout the experiment at $28-29{ }^{\circ} \mathrm{C}$.

\section{Growth of culture of fungus $F$. solani}

For experiments, $F$. solani BKMF-819 was grown in tubes with the beveled maltose agar at $24-25{ }^{\circ} \mathrm{C}$. The sowing of the fungi in the reactor was carried out by flushing with distilled water. Two vials with the grown cultures of the fungi were used for one sample. The temperature of the incubation of the fungi was maintained throughout the experiment at approximately $27-29^{\circ} \mathrm{C}$.

\section{Microbiological destruction of the NC with bacteria cultures}

D. desulfuricans bacteria are conditionally aerobic and, therefore, for the best result they should be used under anaerobic conditions. The experiments on the study of NC biological degradation were carried out in a laboratory glass reactor with a volume of $3 \mathrm{~L}$ under the natural sunlight without air blowing. Such experimental conditions were used with the aim of establishing the degree of possible biotransformation under the conditions extremely favorable for the bacteria. Each reactor contained $500 \mathrm{~mL}$ of the nutrient medium and $50 \mathrm{~mL}$ of the cultivated bacteria. In the first series of the experiments, the reactor was loaded with $10 \mathrm{~g} \mathrm{~L}^{-1}$ of the native NC. In the second series, the reactor contained $10 \mathrm{~g} \mathrm{~L}^{-1}$ of $\mathrm{NC}$, which was pretreated for $27 \mathrm{~h}$ by $\mathrm{UV}$ radiation and ozone $\left(\mathrm{NC}_{\text {proc }}\right)$. The samples for analysis were taken on the 5th, 16th, and 38th day from the onset of experiment in a volume of $50 \mathrm{~mL}$ after mechanical stirring.

\section{Microbiological destruction of the NC with fungi cultures}

The experiments on the study of NC biological degradation were carried out in a laboratory glass reactor with a volume of $3 \mathrm{~L}$ under the natural sunlight without air blowing. Each reactor contained $500 \mathrm{~mL}$ of the nutrient medium seeded with $F$. solani BKM F-819. In the first series of the experiments, the reactor was loaded with $10 \mathrm{~g} \mathrm{~L}^{-1}$ of the native NC. In the second series, the reactor contained $10 \mathrm{~g} \mathrm{~L}^{-1}$ of $\mathrm{NC}$, which was pretreated for $27 \mathrm{~h}$ by UV radiation and ozone $\left(\mathrm{NC}_{\text {proc }}\right)$. The samples for analysis were taken on the 5th, 16th, and 38th day from the onset of the experiment in a volume of $50 \mathrm{~mL}$ after mechanical stirring.

\section{Destruction of NC with a mixed culture of bacteria and fungi}

The experiments on the study of the biological destruction of the $\mathrm{NC}$ at the simultaneous impact of the fungus $F$. solani and bacteria $D$. desulfuricans were conducted in a laboratory glass reactor with a volume of 31 containing $500 \mathrm{~mL}$ of the medium and inoculated with $F$. solani BKMF-819 $(3 \times 2$ tubes with the beveled agar) and $D$. desulfuricans BKMB-1388 $(50 \mathrm{~mL}$ of the culture containing 6.5-8.5 $10^{8}$ cells $\mathrm{mL}^{-1}$ ) under the natural sunlight without air blowing. The $\mathrm{NC}$ was added in the both reactors at a concentration of $10 \mathrm{~g} \mathrm{~L}^{-1}$. In the first series of the experiments, the reactors were loaded with the native NC. In the second series, the reactors contained the $\mathrm{NC}_{\text {proc }}$, which was pretreated by UV radiation and ozone. The samples for analysis were taken on the 5th, 16th, and 38th day from the onset of the experiment in a volume of $50 \mathrm{~mL}$ after mechanical stirring. The temperature was maintained at $25-27{ }^{\circ} \mathrm{C}$ during bacteria and fungi incubation.

The variants considered for the microbiological treatment of the NC are presented in Table 1.

\section{Isolation of the NC from the solution}

The samples $(50 \mathrm{~mL})$ were regularly taken from each laboratory reactor. The precipitate from the culture fluid containing the bacterial cells, insoluble salts, and particles of $\mathrm{NC}$ was separated by centrifugation at $7000 \mathrm{rpm}$ for 20 min in an Optima L-90 K ultracentrifuge (Beckman, USA). Then, the precipitate was washed twice with distilled water and dried to a constant weight at $105^{\circ} \mathrm{C}$. The dry residue was treated with acetone $(50 \mathrm{~mL})$ and left to stay for $2 \mathrm{~h}$ at $40{ }^{\circ} \mathrm{C}$ to attain the complete dissolution of the $\mathrm{NC}$ in acetone. The bacterial cells and insoluble salts from the solution in acetone were separated by repeated 
Table 1 Variants for the study of the microbiological degradation of the NC

\begin{tabular}{ll}
\hline Sample & Variants of microbiological processing \\
\hline $\mathrm{K} 1$ & $\mathrm{NC}$ native (control 1) \\
$\mathrm{NC}_{\mathrm{proc}}-\mathrm{K} 2$ & $\mathrm{NC}+(\mathrm{UV}+$ ozone) for $27 \mathrm{~h}$ (control 2) \\
No. 1 & $\mathrm{NC}+$ bacteria Desulfovibrio desulfuricans \\
No. 2 & $\mathrm{NC}$ proc + bacteria Desulfovibrio desulfuricans \\
No. 3 & $\mathrm{NC}+$ fungi Fusarium solani \\
No. 4 & $\mathrm{NC}$ \\
No. 5 & $\mathrm{NC}+$ bacteria Desulfovibrio desulfuricans + fungi Fusarium solani \\
No. 6 & $\mathrm{NC}_{\text {proc }}+$ bacteria Desulfovibrio desulfuricans + fungi Fusarium solani \\
\hline
\end{tabular}

centrifugation at $7000 \mathrm{rpm}$ for $15 \mathrm{~min}$, and then, the solution was poured into round porcelain cups and evaporated to $50 \%$ volume at $40{ }^{\circ} \mathrm{C}$. Then, an ethanol-water (1:2) mixture was added dropwise to the precipitate of the $\mathrm{NC}$. The NC isolated was dried to a constant weight in an oven at $40{ }^{\circ} \mathrm{C}$.

\section{Characterization}

\section{Quantification of the NC}

The amount of the NC isolated as described above was determined by the gravimetric method. It was found in the blank experiment that the total mass loss of the $\mathrm{NC}$ in the course of dissolution and centrifugation can reach $6 \%$. The parameter $\mathbf{W}(\%)$ corresponding to a decrease in the $\mathrm{NC}$ content in the isolated solutions was calculated using these data by the equation

$\mathbf{W} \%=100 \%-\left(\mathbf{W}_{\text {isolated }}+6\right) \%$

\section{Determination of nitrogen in the NC}

The contents of $\mathrm{C}, \mathrm{H}, \mathrm{N}$, and $\mathrm{S}$ were determined in the fully dried samples of the NC $(0.01 \mathrm{~g})$ using a Vario MICRO cube CHNS/O elemental analyzer (Elementar $\mathrm{GmbH}$, Germany). No sulfur was detected in all the analyzed samples.

\section{Determination of nitrate and nitrite}

The contents of nitrate and nitrite ions in the solution of the culture fluid were determined by the photometric method on a KFK-2MP photocolorimeter (Technocom, Russia). Nitrate ions were determined by measuring the absorbance at the wavelength $\lambda=400 \mathrm{~nm}$ of a yellow-colored complex formed by the reaction of nitrate ions with salicylic acid in a cuvette $2 \mathrm{~cm}$ thick (modified Lurie method [26]). Nitrite ions were determined by measuring the absorbance at the wavelength $\lambda=540 \mathrm{~nm}$ of a red-violet azo dye (diazo compound) in a cuvette $5 \mathrm{~cm}$ thick. The azo dye is formed in the presence of $\alpha$-naphthylamine and sulfanilic acid (modified Lurie method [26]). The content of ions was calculated by the previously obtained calibration curves. The working solutions containing $13.8 \mu \mathrm{g} \mathrm{cm}^{-3}$ of nitrate and $10.4 \mu \mathrm{g} \mathrm{cm}^{-3}$ of nitrite were used, respectively, to plot the curves. Some solutions of the samples were turbid and, hence, they were filtered through a paper filter ("blue ribbon") before measuring.

\section{Determination of the heat release rate and the heat of thermal decomposition of the selected NC samples}

The study of the heat release kinetics in the thermal decomposition of the utilization products of the $\mathrm{NC}$ was performed with a DAC-1-2 automated differential microcalorimeter [27] at $139.8^{\circ} \mathrm{C}$ in a glass pre-evacuated sealed ampule with an internal volume of about $2 \mathrm{~cm}^{3}$. This microcalorimeter is designed and manufactured at the Institute of Problems of Chemical Physics RAS. The instrument can operate under isothermal conditions over a wide range of temperatures from ambient up to $400{ }^{\circ} \mathrm{C}$ and can measure the heat release rate in the range from $10^{-5}$ to $1 \mathrm{~W}$. The ampule had no cold parts, which allowed one to keep all the decomposition products in the reaction zone. The sample weight of the substance under study was $10 \mathrm{mg}$, unless otherwise indicated.

The rate curves were straightened in the coordinates of the first-order autocatalytic reaction $\mathrm{d} \eta / \mathrm{d} t /(1-\eta)$ on $\eta$ [28], which showed that the process can be described by Eq. (2) until the reaction conversion reached about 0.4 (Fig. 1), except for the initial section.

$\frac{\mathrm{d} \eta}{\mathrm{d} t}=k_{1} \cdot(1-\eta)+k_{2} \cdot(1-\eta) \cdot \eta$.

Here, $\eta=\frac{\int_{0}^{t} \frac{\mathrm{d} Q}{\mathrm{~d} t} \cdot \mathrm{d} t}{\int_{0}^{\infty} \frac{\mathrm{d} Q}{\mathrm{~d} t} \mathrm{~d} t}$ is the depth of thermal decomposition of the $\mathrm{NC} ; \frac{\mathrm{d} \eta}{\mathrm{d} t}=\frac{1}{Q_{0}}\left(\frac{\mathrm{d} Q}{\mathrm{~d} t}\right), 1 / \mathrm{h}$ is the reaction rate of thermal decomposition of the $\mathrm{NC} ; \frac{\mathrm{d} Q}{\mathrm{~d} t}, \mathrm{cal} \mathrm{h}^{-1} \mathrm{~g}^{-1}$ is the heat 


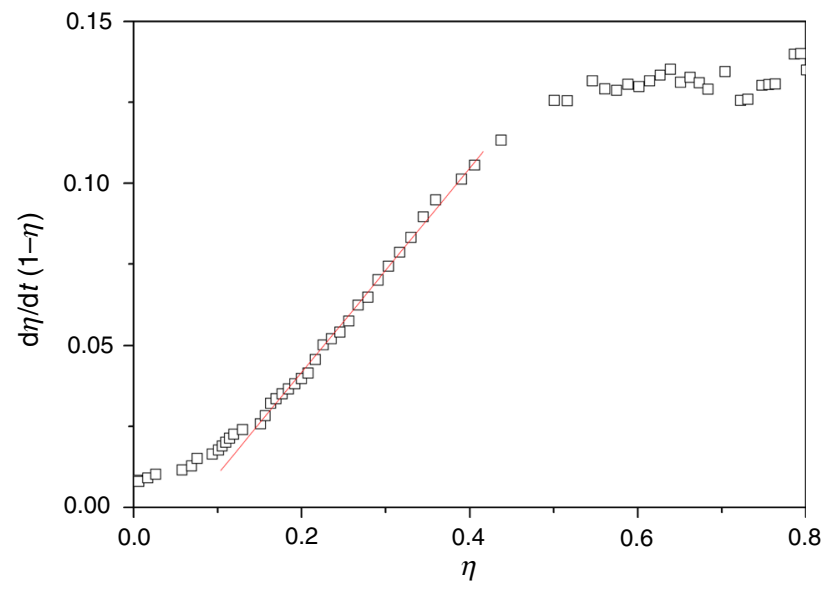

Fig. 1 Dependence of $\frac{\frac{d}{d} t}{1-\eta}$ on $\eta$ for the thermal decomposition of the native NC

release rate; $\int_{0}^{t} \frac{\mathrm{d} Q}{\mathrm{~d} t} \cdot \mathrm{d} t=Q$, cal $\mathrm{g}^{-1}$ is the current heat of the process; $\int_{0}^{\infty} \frac{\mathrm{d} Q}{\mathrm{~d} t} \cdot \mathrm{d} t=Q_{0}$, cal g $^{-1}$ is the full heat of the process, and $k_{1}, 1 / \mathrm{h}$ and $k_{2}, 1 / \mathrm{h}$ are the rate constants of the catalytic and non-catalytic steps of the reaction.

The current heat process $(Q)$ was calculated by the numerical integration of the curve of the heat release rate from zero to the current time, and the full heat $\left(Q_{0}\right)$ was calculated by the integration of the curve from zero to the infinite time value.

\section{Results and discussion}

\section{Degree of biological degradation of the NC}

The data on the change in the nitrogen content in the NC and the contents of nitrate and nitrite ions in the culture fluid solution during incubation are given in Table 2 . In the aqueous solution of the control sample (K1), the nitrite ions were not detected, whereas the content of nitrate ions was 5.94-6.24 $\mu \mathrm{g} \mathrm{mL}^{-1}$.

Before conducting experiments on biological degradation, a portion of the native $\mathrm{NC}$ was subjected to the $\mathrm{UV}+$ ozone treatment for $27 \mathrm{~h}$ [24].

This $\mathrm{NC}_{\text {proc }}$ was the initial in the parallel series of the experiments. In the solution of the control sample (K2) $\mathrm{NC}_{\text {proc }}$, no nitrate ions were detected, whereas in the solution of $\mathrm{NC}_{\text {proc }}$ after $27 \mathrm{~h}$ of the $\mathrm{UV}+$ ozone treatment, the content of nitrite ions was $1.46 \mu \mathrm{g} \mathrm{mL}^{-1}$.

Nitrates are present in the solutions of all the samples in significant quantities, while the content of nitrite ions is negligible (Table 2). It is most likely that these microorganisms consume the nitrite-containing compounds. The highest number of nitrate and nitrite ions was determined in the experiment with the treated $\mathrm{NC}_{\text {proc }}$. It is probably that the pretreatment allows the fungi to penetrate deeper into the polymer globule and, hence, the process of degradation of the NC proceeds more efficiently, in particular, by the cleavage of the $\mathrm{NO}_{2}$ groups [29].

Also, a decrease in the nitrogen content is observed with an increase in the incubation time of the $\mathrm{NC}$ with the microorganisms (Table 2). The lowest nitrogen content in the samples was recorded after the incubation with

Table 2 Change in the contents of elements in the $\mathrm{NC}$ and nitrate and nitrite ions in the solutions during the incubation time with the microorganism

\begin{tabular}{|c|c|c|c|c|c|c|c|c|c|c|c|c|c|c|c|}
\hline \multirow[t]{4}{*}{ Sample } & \multicolumn{9}{|c|}{ Content $/ \%$} & \multicolumn{6}{|c|}{ Content $/ \mu \mathrm{g} \mathrm{mL}^{-1}$} \\
\hline & \multicolumn{3}{|l|}{$\mathrm{C}$} & \multicolumn{3}{|l|}{$\mathrm{H}$} & \multicolumn{3}{|l|}{$\mathrm{N}$} & \multicolumn{3}{|l|}{$\mathrm{NO}_{3}^{-}$} & \multicolumn{3}{|l|}{$\mathrm{NO}_{2}^{-}$} \\
\hline & \multicolumn{3}{|c|}{ Time/day } & \multicolumn{3}{|c|}{ Time/day } & \multicolumn{3}{|c|}{ Time/day } & \multicolumn{3}{|c|}{ Time/day } & \multicolumn{3}{|c|}{ Time/day } \\
\hline & 5 & 16 & 38 & 5 & 16 & 38 & 5 & 16 & 38 & 5 & 16 & 38 & 5 & 16 & 38 \\
\hline K1 & & & & & & & 13.38 & & & $5.94-6$ & & & & & \\
\hline K2 & 25.15 & & & 3.38 & & & 11.67 & & & & & & 1.46 & & \\
\hline No. 1 & 31.72 & 25.97 & 25.99 & 3.97 & 2.89 & 3.11 & 11.57 & 11.72 & 10.77 & 5.80 & 3.23 & 5.55 & $* \mathrm{n} / \mathrm{d}$ & $\mathrm{n} / \mathrm{d}$ & 0.52 \\
\hline No. 2 & 32.05 & 30.61 & 29.40 & 4.83 & 3.83 & 3.79 & 11.17 & 10.92 & 10.58 & 13.00 & 9.01 & 5.06 & $\mathrm{n} / \mathrm{d}$ & $\mathrm{n} / \mathrm{d}$ & 0.20 \\
\hline No. 3 & 30.19 & 25.14 & 26.34 & 3.83 & 2.69 & 3.23 & 11.76 & 10.61 & 10.51 & 11.40 & 5.15 & 2.78 & 3.34 & 0.52 & 0.22 \\
\hline No. 4 & 28.56 & 27.95 & 26.30 & 3.85 & 3.59 & 2.97 & 11.80 & 10.39 & 10.15 & 12.20 & 8.64 & 2.67 & 3.38 & 0.49 & 0.26 \\
\hline No. 5 & 30.23 & 26.26 & 26.68 & 3.84 & 2.94 & 3.26 & 11.57 & 10.92 & 10.28 & 5.70 & 3.08 & 3.03 & $\mathrm{n} / \mathrm{d}$ & $\mathrm{n} / \mathrm{d}$ & 0.25 \\
\hline No. 6 & 31.35 & 28.69 & 27.38 & 4.03 & 3.33 & 3.48 & 11.07 & 10.70 & 10.03 & 23.60 & 9.14 & 6.26 & $\mathrm{n} / \mathrm{d}$ & $\mathrm{n} / \mathrm{d}$ & 0.21 \\
\hline
\end{tabular}

The designation of the samples is listed in Table 1. *n/d means "not detected" 
microorganisms for the period from 16 to 38 days and varied from 10.03 to $10.77 \%$.

In general, it is remarkable that the $\mathrm{NC}_{\text {proc }}$ pretreated by ultraviolet radiation and ozone is degradable to a greater extent than the non-treated one. For example, in sample 1 after 38 days of incubation with bacteria $D$. desulfuricans the content of $\mathrm{N}$ is $10.77 \%$, whereas in sample 2 the content of $\mathrm{N}$ is $10.58 \%$.

The measurements taken over a period of 5 days demonstrate no significant benefits of the UV + ozone pretreatment. After 16 and up to 38 days of the incubation, there is a clear picture that the nitrogen content in the $\mathrm{NC}_{\text {proc }}$ is lower than that in the non-pretreated NC samples.

The data in Table 2 show that during the period from 16 to 38 days, a change in the general trend to the degradation of the NC is observed, namely the biodegradation rate by microorganisms decreases. The observation of all samples was continued up to 65 days. The tendency to decreasing the biodegradation rate established to the 38th day naturally increased. A decrease in the biodegradation rate of the samples with $D$. desulfuricans with incubation time indicates that the bacteria lose the activity. The reasons can be the acidification of the reaction solution or the total consumption of the nutrient medium necessary for the life of bacteria. Therefore, the incubation period up to 38 days is the most technologically justified (without additional fertilizing of microorganisms).

After 38 days, the lowest degree of degradation of the $\mathrm{NC}$ was shown by the samples incubated with one culture of bacteria as in the case of the $\mathrm{NC}$ (sample 1, $[\mathrm{N}]=10.77 \%$ ) and in the case of $\mathrm{NC}_{\text {proc }}$ (sample 2, $[\mathrm{N}]=10.58 \%$ ).

After 38 days of the incubation, the minimum amount of nitrogen was detected in sample 6 and was equal to $10.03 \%$. Thus, the maximum level of degradation was achieved in a series of experiments with the $\mathrm{NC}_{\text {proc }}$ when the mixed culture of bacteria and fungi was used and was equal to $25.04 \%$. A slightly lower level of degradation is shown by sample 4 of the $\mathrm{N}_{\text {proc }}$, which was incubated with one culture of fungi $F$. solani for 38 days. In this case, the $\mathrm{N}$ content is $10.15 \%$ and the degree of degradation of the $\mathrm{NC}$ is $23.39 \%$.

Figure 2 shows that, according to the weighing data, a decrease in the NC content in solution ( $\mathbf{W} \%)$ exceeds the degree of decomposition of the $\mathrm{NC}$, which was determined from the decrease in the nitrogen content in the samples. This difference indicates that the microorganisms perform two different processes, namely the elimination of nitro groups and the breakage of the bonds of the hydrocarbon skeleton and the evolution of the low-molecular fragments.

The total amount of nitrates and nitrites determined within 38 days of incubation with $F$. solani (23.41 $\mu \mathrm{g} \mathrm{mL}^{-1}$ for sample 3 and $28.03 \mu \mathrm{g} \mathrm{mL}^{-1}$ for

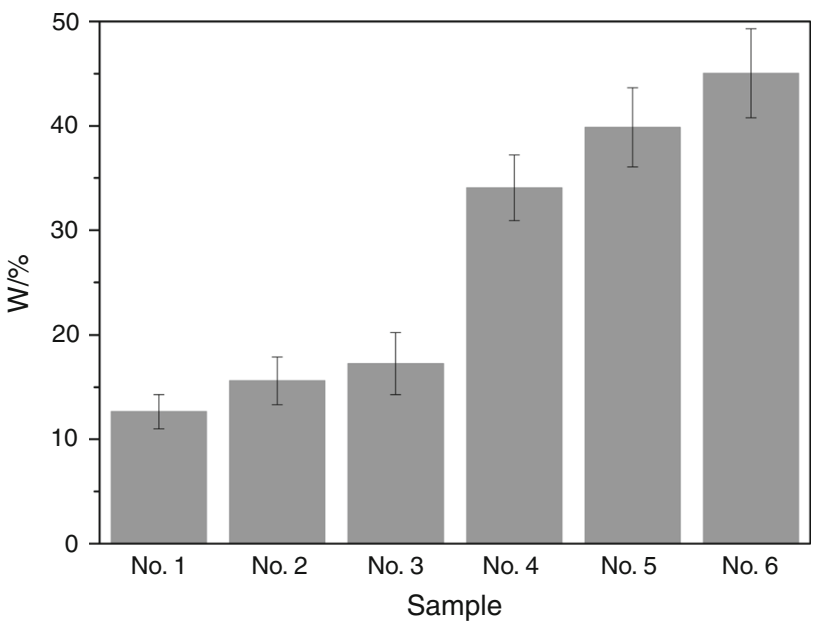

Fig. 2 Change in parameter $\mathbf{W}(\%)$ corresponding to the amount of the $\mathrm{NC}$ isolated from solutions in different variants of microbiological processing after 38 days of the treatment according to weighing the samples. Variants of microbiological processing: (1) sample No. 1; (2) sample No. 2; (3) sample No. 3; (4) sample No. 4; (5) sample No. 5 ; and (6) sample No. 6

sample 4) is higher than that after incubation with $D$. desulfuricans $\left(15.1 \mu \mathrm{g} \mathrm{mL}^{-1}\right.$ for sample 1 and $27.27 \mu \mathrm{g} \mathrm{ml}^{-1}$ for sample 2). This can be explained by the fact that $D$. desulfuricans utilizes nitrates and nitrites as electron acceptors reducing them to $\mathrm{N}_{2}$, which is characteristic of many types of this sulfate-reducing bacteria [30].

As it is given in Table 2, the amount of the NC itself decreases with $\mathrm{NC}$ incubation on microorganisms. The data presented take into account the "blank experiment," i.e., minus $6.0 \%$ that are lost when the NC is isolated from the solution with acetone. For incubation with fungi $F$. solani (samples 3 and 4), the NC degrades to a higher extent than that for incubation with bacteria $D$. desulfuricans. Evidently, the microorganisms decrease the nitrogen content in the studied samples and also substantially transform the NC itself. So, hydrogen sulfide, which is a natural product of metabolism of sulfate-reducing bacteria $D$. desulfuricans, hydrolyzes NC. It is known that $F$. solani is a denitrifying fungus that produces exohydrolase enzymes hydrolyzing nitroester bonds of this polymer. In addition, many fungi including $F$. solani have cellulolytic activity, i.e., can decompose esters. However, the efficiency of hydrolysis of nitroester bonds is low under aerobic conditions without the preliminary physicochemical treatment [18]. This is observed in our experiments: In samples 2, 4, and $6, \mathrm{NC}_{\text {proc }}$ is taken, since much more $\mathrm{NC}_{\mathrm{proc}}$ is removed than in the variant with the non-processed NC.

Thus, the functions of microorganisms are diverse. They hydrolyze nitroester bonds resulting in a decrease in the degree of nitration of the polymer and destruct the carbon chain at the $\beta$-1,4-glycoside bond to form nitrooligosaccharides of various lengths [31, 32]. As a result, the overall 
losses of the NC (Fig. 2) increase to $39.85 \%$ (for NC) and $45.03 \%$ (for $\mathrm{NC}_{\text {proc }}$ ) under the combined action of bacteria and fungi. However, the preliminary processing (UV + ozone) favors a deeper penetration of microorganisms into the polymer globule and increases the degree of degradation of the NC.

The results obtained make it possible to build a sequence of the efficiency of the microorganisms used for the biological degradation of the NC: bacteria $D$. desulfuricans $<$ fungi $F$. solani $<$ bacteria $D$. desulfuricans + fungi $F$. solani.

The scatter of the data on the changes in the contents of nitrogen, nitrate ions, and nitrite ions in the $\mathrm{NC}$ solutions indicates that the microorganisms assimilate the $\mathrm{NC}$ with different rates. For isolation from the reaction solution with acetone, mainly non-damaged macromolecules are extracted, whereas destroyed pieces of the NC can remain in the reaction solution.

To answer the question about the degree of degradation of the NC, the degradation was monitored using another parameter characterizing the process, namely the heat of thermal decomposition of the extracted and isolated samples of the NC after biodegradation.

\section{Thermal decomposition kinetics of the NC after different microbiological treatment options}

\section{Treatment by ultraviolet light and ozone}

Calorimetric measurements make it possible to establish the amount of released heat and the heat release rate for specific experimental conditions. The data obtained indirectly indicate the degree of degradation of the NC. The calorimetric parameters of the native $\mathrm{NC}$ sample were

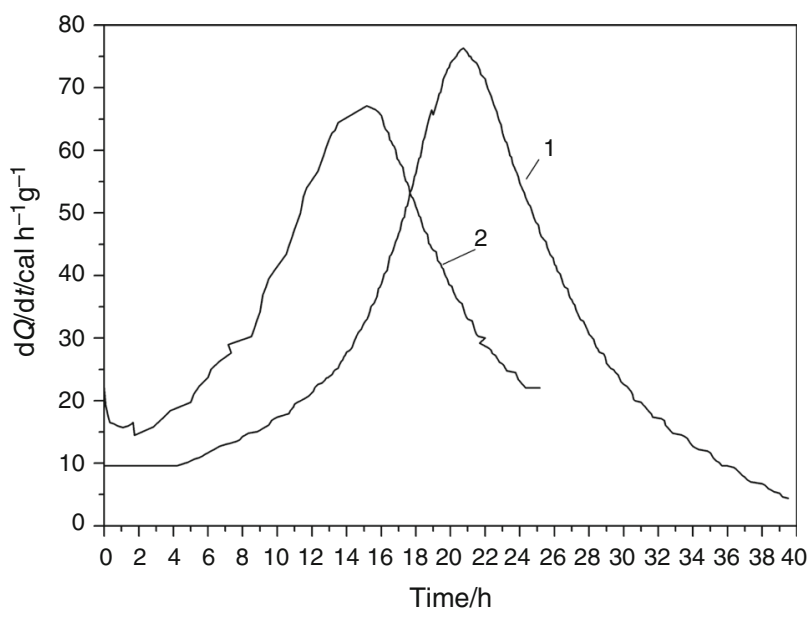

Fig. 3 Dependences of the heat release rate on time during the thermal decomposition of the $\mathrm{NC}$ samples at $139.8^{\circ} \mathrm{C}$. (1) Native $\mathrm{NC}$ (control 1); (2) $\mathrm{NC}_{\text {proc }}$ (control 2) compared with those obtained for the NC samples studied after preliminary biological processing under different conditions.

The dependences of the heat release rate on time during the thermal decomposition are shown in Fig. 3.

It can be seen from the dependences presented (Fig. 1) that the thermal decomposition of the samples studied proceeds according to the law of autocatalytic reaction with the degree of acceleration (ratio of the maximum rate to the initial one) about 6 .

As shown in Fig. 3, there is a slight increase in the initial rate of thermal decomposition of the irradiated $\mathrm{NC}_{\text {proc }}$ (control 2). This leads to a decrease in the time of achievement of the maximum rate [27, 33]. The full heat release of the native $\mathrm{NC}$ is about $1110 \mathrm{cal} / \mathrm{g}_{\mathrm{NC}}$ on the average. The heat of $\mathrm{NC}_{\text {proc }}$ decomposition is slightly lower and equal to $1010 \mathrm{cal} / \mathrm{g}_{\mathrm{NC}}$. This value can serve as an indirect indication of the fact that the UV + ozone treatment of the NC leads to the separation of the nitro groups. The further confirmation of this fact is a strong decrease in the $\mathrm{pH}$ in the UV treatment according to [19].

A small increase in the initial rate of the thermal decomposition of the irradiated $\mathrm{NC}$ is probably due to changes in the supramolecular structure of the $\mathrm{NC}$ in the NC irradiation process [19]. In turn, the increase in the initial rate leads to the shortening of the time of achievement of the maximum rate in the $\mathrm{NC}_{\text {proc }}$ decomposition reaction [27]. As a result of the separation of nitro groups $[19,24]$, there is a decrease in the total heat of thermal decomposition of the $\mathrm{NC}_{\text {proc }}$.

\section{Incubation with $D$. desulfuricans bacteria, fungi $F$. solani, and mixed cultures}

The recovery of the $\mathrm{ONO}_{2}$ groups in the $\mathrm{NC}$ is a key reaction reducing its toxicity and paving the way for further deep transformations. Conventionally, aerobic bacteria $D$. desulfuricans form a specialized group of microbes that use sulfate $\left(\mathrm{SO}_{4}{ }^{2-}\right)$ as the final electron acceptor during respiration. The sulfate-reducing bacteria are able to recover nitroxy groups to ammonium by the dissimilation mechanism [34]. Therefore, it was proposed [15] to use the strain of the genus Desulfovibrio as the primary link in the microbial consortium for initiating the $\mathrm{NC}$ degradation process under the conditions of plant effluents, since the latter contain significant amounts of sulfates [15].

For the biological treatment of effluents of the pulp industry, microorganisms need to grow rapidly, predominate competitively in the environment, and degrade in low and high molecular weight derivatives of lignin. In particular, it is shown [35] that cellulolyticus (S. rolfsii ATCC 24459 ) and the denitrifying fungus ( $F$. solani IFO 31093) can aerobically decompose $\mathrm{NC}$ in a liquid medium. 
However, it should be remembered that the degradation of $\mathrm{NC}$ is influenced by many factors that can limit its utilization.

On this basis, the options of the biological degradation of the NC by incubation on the bacteria $D$. desulfuricans (sample 1, Table 1) and the fungus $F$. solani (sample 3), as well as at their combined action (sample 5), were reviewed. In parallel, their effect on the $\mathrm{NC}_{\text {proc }}$ (samples 2, 4, and 6) was tested. For the isolated $\mathrm{NC}$ and $\mathrm{NC}_{\text {proc }}$, the rate and thermal effect of their thermal decomposition were studied with the purpose to reveal the conversion of their microbiological processing.

Figure 4 presents the dependences obtained for the maximum heat release rate during the thermal decomposition of the NC for the samples incubated with microorganisms over a period of 38 days. It was established experimentally that the decomposition proceeds via the law of the autocatalytic reaction for both the native $\mathrm{NC}$ and the $\mathrm{NC}$ subjected to microbiological processing in all the variants.

Figure 4 shows that the heat release rate during the decomposition of samples 1 and 2 pre-incubated with bacteria $D$. desulfuricans differs from that for the decomposition of the native NC to the lowest extent. The incubation with the culture of the fungus $F$. solani results in a significantly higher effect, and the thermal decomposition rate of samples 3 and 4 significantly decreases as compared with the control. Finally, under the combined action of the bacteria and fungi the thermal decomposition rate decreases even more strongly $\left(\mathrm{NC}_{\text {proc }}\right.$, sample 6).

The initial heat release rate $(\mathrm{d} Q / \mathrm{d} t) t=0$ is 14-15 cal h $\mathrm{h}^{-1} \mathrm{~g}^{-1}$ on the average, and its deviation in the

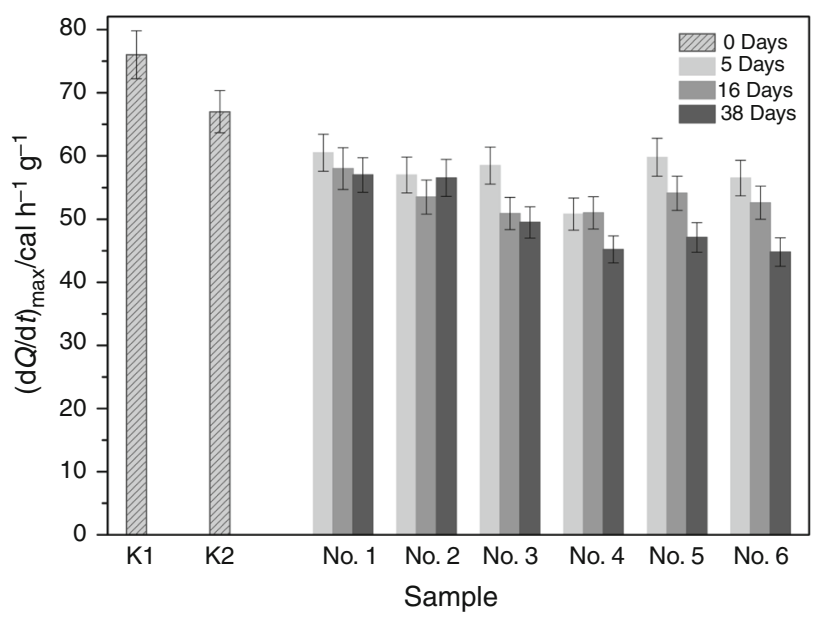

Fig. 4 Change in the maximum of the heat release rate during the thermal decomposition of the $\mathrm{NC}$ samples at $139.8^{\circ} \mathrm{C}$ on the time of the preceding treatment ( $0-38$ days) at different variants of microbiological processing: $\mathrm{K} 1$ is native $\mathrm{NC}$ and $\mathrm{K} 2$ is $\mathrm{NC}_{\text {proc }}$; (1) sample No. 1; (2) sample No. 2; (3) sample No. 3; (4) sample No. 4; (5) sample No. 5; and (6) sample No. 6 increase direction is observed for microbiological treatment options 2, 4, and 6 for incubation for 38 days. The maximum heat release rate $(\mathrm{d} Q / \mathrm{d} t)_{\max }$ is about $60 \mathrm{cal} \mathrm{h}^{-1} \mathrm{~g}^{-1}$ on the average. The heat release rates for sample 1 are higher.

The time of achievement of the maximum heat release rate $t_{\max }$ in the decomposition of the NC after microbiological processing for 38 days for sample 2 is minimum being $13.2 \mathrm{~h}$ (Fig. 5). This time is maximum for sample 3 and equal to $17.9 \mathrm{~h}$. For the control samples, the time is 20.8 and $14.0 \mathrm{~h}$ for $\mathrm{K} 1$ and $\mathrm{K} 2$, respectively. For all the treatment options, $t_{\max }$ for 38 days of the incubation is shorter than that for 16-day processing. The shortest time for the achievement of the maximum heat release rate in NC decomposition after microbiological processing for 38 days is observed for sample 2 . This is probably due to the highest initial rate of decomposition.

Figure 6 shows the dependence of the total heat $\left(Q_{\text {tot }}\right.$, cal $\mathrm{g}^{-1}$ ) released in the thermal decomposition of the isolated NC on the incubation time in different variants of the biological treatment. It is seen that the $\mathrm{UV}+$ ozone pretreatment leads to the situation that $\mathrm{NC}_{\text {proc }}$, in general, has a lower heat of thermal decomposition than the native one.

Figure 6 shows that for the entire set of microbial variants for NC processing, the incubation of samples 3 and 6 with the microorganisms for 38 days leads to a lower heat of thermal decomposition $\left(Q_{\text {tot }}\right)$ and, hence, to a smaller content of nitrogen in the NC dissolved in acetone.

The conducted calorimetric measurements clearly demonstrate serious changes that occur with an NC molecule during incubation on the microorganisms. The change in the character of heat release, namely a decrease in the total released heat and a considerable decrease in the heat

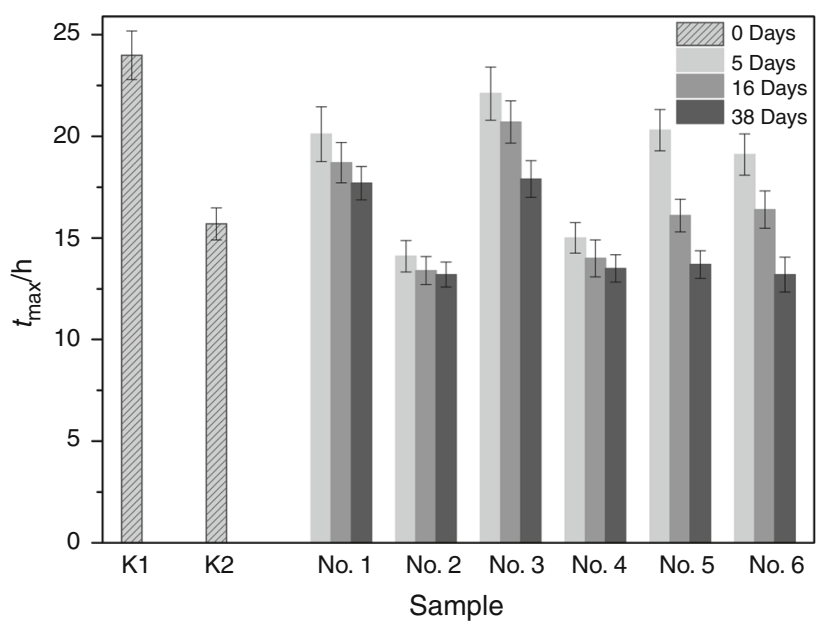

Fig. 5 Change in the time of achievement of the maximum heat release rate during the thermal decomposition of the $\mathrm{NC}$ samples at different variants of microbiological processing: $\mathrm{K} 1$ is native $\mathrm{NC}$ and $\mathrm{K} 2$ is $\mathrm{NC}_{\text {proc }}$; (1) sample No. 1; (2) sample No. 2; (3) sample No. 3; (4) sample No. 4; (5) sample No. 5; and (6) sample No. 6 


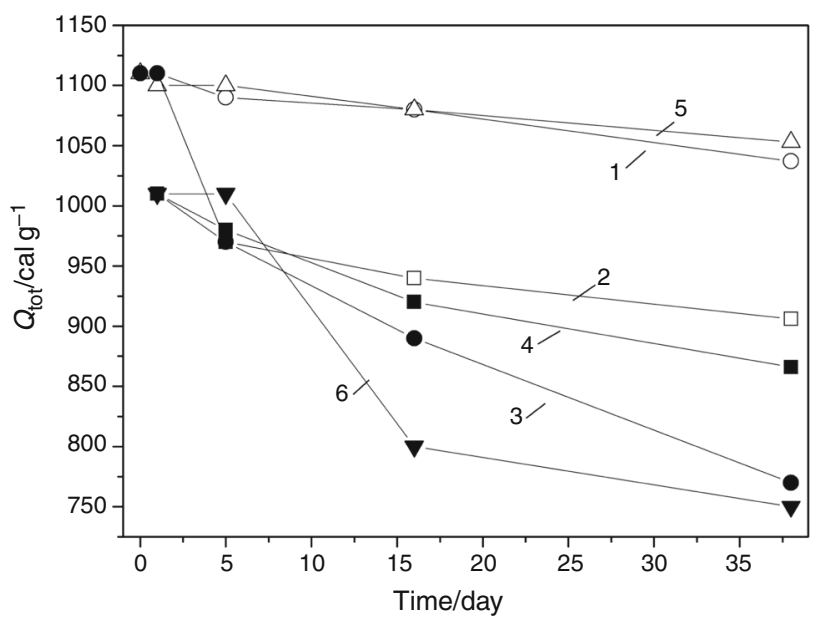

Fig. 6 Change in the total heat $\left(Q_{\mathrm{tot}}, \mathrm{cal} \mathrm{g}^{-1}\right)$ released in the thermal decomposition of the selected samples of the $\mathrm{NC}$ at $139.8^{\circ} \mathrm{C}$ depending on the incubation time in various options of the biological treatment: (1) sample No. 1; (2) sample No. 2; (3) sample No. 3; (4) sample No. 4; (5) sample No. 5; and (6) sample No. 6

release rate, proves that the NC undergoes microbiological transformation into the stationary phase of microorganism growth. Nitrates and cellobiose are formed due to the action of enzymes and metabolites of the used fungi and bacteria. As a result, the parameters inherent in the $\mathrm{NC}$ as an explosive decrease significantly. Undoubtedly, the products of $\mathrm{NC}$ transformation have some intrinsic heat of decomposition, and it is difficult to isolate and estimate quantitatively their contribution. However, according to the available literature data [36], the amount of released heat in cal $\left(Q_{\text {tot }}\right)$ corresponds rather exactly to the nitrogen content in the NC. Evidently, the data of the calorimetric measurements confirm the qualitative pattern of activity of the studied microorganisms toward the NC:

bacteria $D$. desulfuricans $<$ fungi $F$. solani $<$ bacteria

$D$. desulfuricans + fungi $F$. solani.

In this report, it has been shown for the first time that the preliminary treatment with UV + ozone favors the subsequent biological degradation of the NC. An attempt to use the physical treatment of this kind was made earlier. An attempt to use this type of physical treatment was made in [37]. However, there is a basic distinction between our work and [24]. We treated the NC with UV radiation, while the authors [24] first treated the wastewater containing NC with alkali (alkaline hydrolysis occurred) and only them subjected the alkali-treated NC with UV radiation.

The screening of the microorganisms to nitroesterase activity revealed active producents of exohydrolase enzymes hydrolyzing nitroester bonds of xenobiotic among various taxonomic groups of pro- and eukaryotes: Pseudomonas fluorescens [17], Escherichia coli, Bacillus circulans, Rhodococcus rubropertinctus, and in culture mixture Desulfovibrio desulfuricans $[15,16]$. The biodegradation of NC was conducted [18] by incubation in a culture mixture with the methanogenically enriched culture. In 11 days of incubation, the content of $\mathrm{N}$ (\% and equal weight amount) decreased from 13.3 to $10.1 \%$. Under the conditions where bacteria were additionally fed with lactate, the decrease in the NC within 60 days was more than $25 \%$.

It is shown [38] that the bacteria Desulfovibrio desulfuricans ATCC 27774 can grow in the presence of an almost atmospheric content of oxygen. Since the wastewaters of the NC production contain significant amounts of sulfates, the bacteria Desulfovibrio are very interesting from the viewpoint of their possible practical use. For NC with a nitrogen content of $11.8 \%$ [15], the decrease in the NC within 60 days of incubation was $28.1 \%$ and the nitrogen content decreased by $2-6 \%$.

The decrease in the NC amount from 12.65 to $15.59 \%$ obtained in this work with a decrease in the nitrogen content by $3 \%$ in samples 1 and 2 for 38 days of incubation for $D$. desulfuricans without the addition of the nutrient medium can be considered consistent with the available literature data.

The fungi cultures, including Fusarium solani, are most efficient from the viewpoint of biodegradation of $\mathrm{NC}$ $[34,39]$. The degree of degradation of the $\mathrm{NC}$ equal to $23.6 \%$ (initially $[\mathrm{N}]=13.17 \%$ ) and losses of $0.3 \% \mathrm{~N}$ within 7 days of incubation on $F$. solani with the addition of starch as a cosubstrate were obtained [39]. The maximum degree of degradation was $24.8 \%$ during the incubation time shorter than 7 days on fungi of other types: Acremonium persicinum ATCC 60921, Basidiomycetes sp. NRRL 6464, Bjerkandera adusta ESF 620, Cyathus stercoreus NRRL 6473, Irpen lacteus Z 212, Phanerochaete chrysosporium ATCC 32629, Trametes versicolor ESF 491, and Trichoderma pseudokoningii FTK 228 [39]. The further increase in the degree of degradation of the $\mathrm{NC}$ is achieved for increasing the incubation time in the presence of nutrient medium for microorganism growth, for example, $43 \%$ within 28 days (initially $[\mathrm{NC}]=13.4 \% \mathrm{~N}$, carboxymethylcellulose as a cosubstrate) for incubation on Chaetomium elatum [40].

Thus, a decrease in the NC content by $34 \%$ (sample 4) obtained in this work with a decrease in the nitrogen content by $3 \%$ can be considered as a serious achievement.

The attempts to create a symbiosis of microorganisms for the maximum efficient degradation of NC are known. For the combined incubation on $F$. solani and Sclerotium rolfsii ATCC 24459, the $31 \%$ NC degradation was achieved [35] within 3 days (initially [N] $=13.17 \%$, starch as cosubstrate).

It was also attempted to create a symbiosis of microorganisms: bacteria and fungi. It is seen from the 
obtained data that we failed to obtain the symbiosis: There is no significant increase in the degree of degradation of the $\mathrm{NC}$ with a simultaneous decrease in the nitrogen content in the variant of combined incubation on the bacteria and fungi compared with the incubation by fungus $F$. solani only. However, the achieved degree of degradation, namely a decrease in the $\mathrm{NC}$ amount to $39.85 \%$ and $45.03 \%$ in experiments on the native $\mathrm{NC}$ and $\mathrm{NC}_{\text {proc }}$ (experiments 5 and 6 , respectively), can be considered substantial.

\section{Conclusions}

The oxidation of nitrocellulose (NC) containing 13.38\% nitrogen has been investigated. The process of heat release in the samples of nitrocellulose subjected to biological processing of different types was studied. Biological processing was conducted by incubation with sulfate-reducing bacteria Desulfovibrio desulfuricans BKMB-1388, microscopic fungi Fusarium solani BKM F-819, and their mixed culture. It has been shown that the pretreatment of NC by $\mathrm{UV}+$ ozone significantly increases the degree of degradation of the NC during its subsequent biodegradation assisted by symbiotic microorganisms of $D$. desulfuricans and $F$. solani. The present work provides the following results.

The complete NC degradation was not achieved within the studied terms of incubation (from 5 to 38 days).

The use of the NC pretreated with UV + ozone significantly favors a decrease in the NC content after incubation with all considered biological substrates.

The most substantial results of NC degradation were achieved for the destruction of the NC with the mycelial fungus $F$. solani (samples No. 3 and No. 4).

The denitration of the NC by the combined action of the studied microorganisms (bacteria $D$. desulfuricans, mycelial fungus $F$. solani) was obtained on the NC pretreated with UV + ozone (sample No. 6).

The heat release kinetics in the thermal decomposition of the NC samples isolated after incubation on the microorganisms was studied. The degree of degradation of the NC was estimated by a comparison of the heats of decomposition and a decrease in the amounts of NC and nitrogen. These data made it possible to construct the sequence of efficiency of the microorganisms used for the biological oxidation of $\mathrm{NC}$ : bacteria $D$. desulfuricans $<$ fungi $F$. solani $<$ bacteria $D . \quad$ desulfuricans + fungi $F$. solani.

Substantial parameters were achieved within the incubation period of $\mathrm{NC}_{\text {proc }}$ on the combined culture of bacteria and fungi for the first 5 days, which is promising from the viewpoint of practical use.

\section{References}

1. Isaev AV, Drabkin AV. History of the Great Patriotic War 1941-1945. Moscow: Eksmo; 2018.

2. United Nations Disarmament Yearbook 2004. New-York: United Nations Publications; 2007.

3. Mirzajani V, Farhadi K, Pourmortazavi SM. Catalytic effect of lead oxide nano- and microparticles on thermal decomposition kinetics of energetic composition containing TEGDN/NC/DAG. J Therm Anal Calorim. 2018;131(2):937-48.

4. Trache D, Khimeche K, Mezroua A, Benziane M. Physicochemical properties of microcrystalline nitrocellulose from Alfa grass fibres and its thermal stability. J Therm Anal Calorim. 2016;124(3):1485-96.

5. Li YC, Yang HT, Hong Y, Yang Y, Cheng Y, Chen HH. Electrospun nanofiber-based nanoboron/nitrocellulose composite and their reactive properties. J Therm Anal Calorim. 2017;130(2):1063-8.

6. Guo ML, Ma ZL, He LM, He W, Wang YW. Effect of varied proportion of GAP-ETPE/NC as binder on thermal decomposition behaviors, stability and mechanical properties of nitramine propellants. J Therm Anal Calorim. 2017;130(2):909-18.

7. Wu YG, Ge Z, Luo YJ. Properties and application of a novel type of glycidyl azide polymer modified double-base spherical powders. J Therm Anal Calorim. 2016;124(1):107-15.

8. Wu YG, Yi ZC, Luo YJ, Ge Z, Du FP, Chen S, Sun J. Fabrication and properties of glycidyl azide polymer-modified nitrocellulose spherical powders. J Therm Anal Calorim. 2017;129(3):1555-62.

9. Gallo B, Allen A, Bagalawis RL, Woodbury C, Yang A, Austin P, Kaplan D. Microbial degradation of nitrocellulose. In: Proceedings on nitrocellulose-fines, separation and treatment Champaign, IL: US Army Construction Engineering Research Laboratory, US Army-Purdue University, West Lafayette; 1993. p. 78-91.

10. White GF, Snape JR. Microbial cleavage of nitrate esters; defusing the environment. J Gen Microbiol. 1993;139:1947-57.

11. Riley PA, Kaplan DL, Kaplan AM. Stability of nitrocellulose to microbial degradation. Technical Report No. 85-004, US Army Natick Research Development and Engineering Center, Natick, MA; 1984.

12. Zaripov SA, Naumov AV, Suvorova ES, Garusov AV, Naumova RP. Initial stages of 2,4,6-trinitrotoluene transformation by microorganisms. Microbiology. 2004;73(4):398-403.

13. Binder M, Justo A, Riley R, Salamov A, López-Giráldez F, Sjökvist E, Copeland A, Foster B, Sun H, Larsson E, Larsson KH, Townsend J, Grigoriev IV, Hibbett DS. Phylogenetic and phylogenomic overview of the polyporales. Mycologia. 2013;105(6):1350-73.

14. Novotný Č, Cajthaml T, Svobodová K, Šušla M, Šašek V. Irpex lacteus, a white-rot fungus with biotechnological potential. Folia Microbiol. 2009;54(5):375-90.

15. Petrova OE, Davydova MN, Tarasova NB, Muhitova FK. Sulphate-reducing bacteria in biological treatment of industrial waste containing nitrocellulose. Mosc Univ Chem Bull. 2003;44(1):43-5.

16. Giacomucci L, Toja F, Sanmarti'n P, Toniolo L, Prieto B, Villa F, Cappitelli F. Degradation of nitrocellulose-based paint by $D e$ sulfovibrio desulfuricans ATCC 13541. Biodegradation. 2012;23:705-16.

17. Gershman MD, Kennedy DJ, Noble-Wang J. Multistate outbreak of Pseudomonas fluorescens bloodstream infection after exposure to contaminated heparinized saline flush prepared by a compounding pharmacy. Clin Infect Dis. 2008;47(11):1372-9. 
18. Freedman DL, Cashwell JM, Kim BJ. Biotransformation of explosive-grade nitrocellulose under denitrifying and sulfidogenic conditions. Waste Manag. 2002;22(3):283-92.

19. Saratovskikh EA, Kazakov AI, Kulikov AV, Yarullin RN. Effect of UV treatment on biodegradation of nitrocellulose by $D$. desulfuricans bacteria. Russ J Gen Chem. 2016;60(4):106-15.

20. Tabacof A, Araujo C, Vernoica M. Thermogravimetric analysis and differential scanning calorimetry for investigating the stability of yellow smoke powders. J Therm Anal Calorim. 2017;128(1):387-98.

21. Hosseini SG, Eslami A. The exploration of the influence of microencapsulation processing parameters on the stabilization of ammonium azide particles. J Therm Anal Calorim. 2016;126(2):455-66.

22. Park SSh, Hwang IS, Kang MS, Jeong HJ, Hwang J. Thermal decomposition characteristics of expired single-based propellant using a lab-scale tube furnace and a thermo-gravimetric analysis reactor. J Therm Anal Calorim. 2016;124(2):657-65.

23. Moura Torquato LD, Almeida S, Oliveira JE, Crespi MS, Maintinguer SI. Thermal characterization of anaerobic sludges from wastewater treatments applied to biological generation of $\mathrm{H}_{2}$. J Therm Anal Calorim. 2017;127(2):1267-75.

24. Khryachkov VA, Saratovskikh EA, Yarullin RN, Kulikov AV. Effect of the $D$. desulfuricans bacterium and UV radiation on nitrocellulose oxidation. Russ J Phys Chem B. 2017;11(4):697-703.

25. Saratovskikh EA, Shcherbakova VA, Yarullin RN. Destruction of cellulose nitrate by fungi Fusarium solani. Russ Appl Biochem Microbiol. 2018;54(1):55-62.

26. Lurie YY. Analytical Chemistry of Industrial Waste Water. Moscow: Chemistry; 1984.

27. Galuk OS, Rubtzov YuI, Malinovskaya GF, Manelis GB. Microcalorimeter for study the kinetics of chemical reactions. Russ J Phys Chem A. 1965;39:2319-22.

28. Binke N, Rong L, Zhengquan Y, Yuan W, Pu Y, Rongzu H, Qingsen Y. Studies on the kinetics of the first order autocatalytic decomposition reaction of highly nitrated nitrocellulose. J Therm Anal Calorim. 1999;58(2):403-11.

29. Orlova EY. Chemistry and Technology of High Explosives. Leningrad: Chemistry; 1973.

30. Gonzalez PJ, Correia C, Moura I, Brondino CD, Moura JJG. Bacterial nitrate reductases: molecular and biological aspects of nitrate reduction. J Inorganic Biochem. 2006;100(5):1015-23.

31. Ilinskaya ON, Chernov PP, Leshchinskaya IB. Decomposition of nitrocellulose by a community of microorganisms immobilized on it. Sci Rep High Sch Biol Sci. 1988;6:87-93.

32. Gonzalez PJ, Correia C, Moura I, Brondino CD, Moura JJG. Bacterial nitrate reductases: molecular and biological aspects of nitrate reduction. J Inorganic Biochem. 2006;100(5):1015-23.

33. Zakonzchikov AP. Nitrocellulose. Moscow: Oborongis; 1950.

34. Dalsgaard T, Bak F. Nitrate reduction in a sulfate-reducing bacterium Desulfovibrio desulfuricans, isolate from rice paddy soil: sulfide inhibition, kinetics and regulation. Appl Environ Microbiol. 1994;60(1):291-7.

35. Sharma A, Sundaram ST, Zhang Y-Z, Brodman BW. Nitrocellulose degradation by a coculture of Sclerotium rolfs $f$ and Fusarium solani. J Ind Microbiol. 1995;15:1-4.

36. Sopin VF, Gatina RF, Khatsrinov AI, Klimovich OV, Romanko NA, Omarov ZK, Pelitmintseva EG, Namestnikov VV. Method of nitrogen determination in nitrates of cellulose. Butlerov Rep. 2006;10(7):64-9.

37. Barreto-Rodrigues M, Souza JV, Silva ÉS, Silva FT, Paiva TC. Combined photocatalytic and fungal processes for the treatment of nitrocellulose industry waste water. J Hazard Mater. 2009;161(2-3):1569-73.

38. Lobo SAL, Melo AMP, Carita JN, Teixeira M, Saraiva LM. The anaerobe Desulfovibrio desulfuricans ATCC 27774 grows at nearly atmospheric oxygen levels. FEBS Lett. 2007;581:433-6.

39. Sundaram ST, Zhang YZ, Sharma A, Ng K, Brodman BW. Screening of mycelial fungi for nitrocellulose degradation. J Appl Polym Sci. 1995;58(12):2287-91.

40. Auer N, Hedger JN, Evans ChS. Degradation of nitrocellulose by fungi. Biodegradation. 2005;16:229-36. 